\title{
Need for permanent pacemaker implantation following implantation of the rapid deployment valve in combined procedures: a single centre cohort study
}

\author{
Oliver Deutsch $^{1,2}$, Isabell Deisenhofer ${ }^{3}$, Katharina Koch-Buettner ${ }^{3}$, Rüdiger Lange ${ }^{1,2,4}$, Markus Krane ${ }^{1,2,4}$ \\ ${ }^{1}$ Department of Cardiovascular Surgery, German Heart Centre Munich of the Technical University Munich, Munich, Germany; ${ }^{2}$ INSURE (Institute \\ for Translational Cardiac Surgery), German Heart Centre Munich, Munich, Germany; ${ }^{3}$ Department of Cardiology, German Heart Centre Munich \\ of the Technical University Munich, Munich, Germany; ${ }^{4}$ DZHK (German Centre for Cardiovascular Research)-Partner Site Munich, Munich Heart \\ Alliance, Munich, Germany \\ Contributions: (I) Conception and design: O Deutsch, M Krane; (II) Administrative support: M Krane, R Lange; (III) Provision of study materials or \\ patients: M Krane, R Lange; (IV) Collection and assembly of data: O Deutsch, K Koch-Buettner; (V) Data analysis and interpretation: O Deutsch, I \\ Deisenhofer, M Krane, R Lange; (VI) Manuscript writing: All authors; (VII) Final approval of manuscript: All authors. \\ Correspondence to: Oliver Deutsch, MD. German Heart Centre Munich, Lazarettstr. 36, 80636 Munich, Germany. Email: deutscho@dhm.mhn.de.
}

Background: Rapid deployment aortic valves may interfere with the cardiac conduction system. We investigated the need for permanent pacemaker implantation (PPI) following the implantation of Edwards INTUITY valve (Edwards Lifesciences, Irvine, CA).

Methods: One hundred twenty patients underwent aortic valve replacement (AVR) with the INTUITY valve in a combined procedure at the German Heart Centre Munich between April 2016 and December 2019. Twenty-four patients with prior PPI or concomitant ablation procedures (24/120, 20\%) were excluded. Patient-specific, procedural and post-procedural outcomes were assessed in the remaining 96 cases.

Results: AVR was successful in all cases. Seventy-four percent of the study population were men. Mean age was $69.5 \pm 7.6$ years. EuroSCORE II was 3.2 \pm 2.9 . Forty-six patients $(46 / 96,47.9 \%)$ presented with preoperative conduction disorders, right bundle branch block (RBBB) (17/96, 17.7\%) and first-degree or second degree atrio-ventricular block (AVB) $(18 / 96,18.8 \%)$, in particular. In total, 9 patients $(9 / 96,9.4 \%)$ underwent PPI. PPI was required in 3 patients (3/50, 6.0\%) who did not have a pre-existing conduction disorder due to new high degree AVB. 6 patients with pre-operative conduction disorders $(6 / 46,13 \%)$ needed PPI. Timing of PPI was $5.2 \pm 1.5$ days (median 5). Independent predictors of PPI were preoperative $\mathrm{RBBB}$ [odds ratio $(\mathrm{OR})=4.554, \mathrm{P}=0.049$ ] and large valve size $(\# 27)(\mathrm{OR}=5.527, \mathrm{P}=0.031)$.

Conclusions: The analysis of the data collected enabled us to identify patient factors associated with higher risk for post-operative PPI following AVR with the INTUITY valve. Patient factors associated with post-operative PPI, were RBBB and large valve size. These patients should be closely monitored following the procedure, in particular.

Keywords: Rapid deployment valve; aortic valve replacement (AVR); permanent pacemaker implantation (PPI)

Submitted Oct 02, 2020. Accepted for publication Jan 15, 2021.

doi: $10.21037 /$ jtd-20-3120

View this article at: http://dx.doi.org/10.21037/jtd-20-3120

^ ORCID: 0000-0003-4143-8140. 


\section{Introduction}

Surgical rapid deployment valves have been developed, in order to facilitate surgical aortic valve replacement (AVR). They have significantly reduced cross clamp and cardiopulmonary bypass times and are more suitable for minimally invasive AVR and combined procedures $(1,2)$. The Edwards INTUITY surgical rapid deployment valve (Edwards Lifesciences, Irvine, CA) is a construct of a surgical bioprosthesis which is extended with a cobaltchromium alloy balloon expandable stent. The stent extension which is essential for valve anchoring may interfere with the conduction system of the heart and therefore may result in a higher need for permanent pacemaker implantation (PPI). The incidence of all cause PPI prior to discharge with the Edwards INTUITY surgical rapid deployment valve was reported to be $11.9 \%$ with the need for PPI predominantly occurring early after surgery (3-5).

We sought to determine the incidence, risk factors and indications for PPI in a large retrospective single centre cohort receiving AVR with the rapid deployment Edwards INTUITY valve system in combined procedures. We present the following article in accordance with the STROBE reporting checklist (available at http://dx.doi. org/10.21037/jtd-20-3120).

\section{Methods}

\section{The Edwards INTUITY Valve System}

The Edwards INTUITY Valve System design is based upon a Carpentier-Edwards PERIMOUNT Magna Ease Pericardial Aortic Bioprosthesis. This design is modified with an attached pre-crimped, cloth-covered balloonexpandable cobalt-chromium alloy frame. After standard annular debridement and excision of the diseased native valve the implantation includes the placement of three locking sutures and balloon deployment of the sub-annular frame. The valve design may translate into a simpler and faster implantation, making it suitable for minimally invasive surgical approaches and combined procedures, in particular. The Edwards INTUITY Valve System is available in $19,21,23,25$, and $27 \mathrm{~mm}$ sizes.

\section{Data collection and ethics}

Clinical data of all patients receiving AVR with Edwards INTUITY Valve System was retrieved from our institutional database. During the study period between April 2016 and December 2019 a total of 120 patients underwent AVR with the INTUITY valve system in a combined procedure. Patient-specific, procedural and post-procedural outcomes were assessed. Preoperative, operative data and findings at postoperative follow-up were analyzed. We specifically excluded those patients with prior pacemaker implantation and patients with concomitant ablation procedures for this study. The remaining 96 patients represent our investigational cohort (Figure 1).

The study was conducted in accordance with the Declaration of Helsinki (as revised in 2013). The study was approved by institutional ethics committee (Technical University Munich, Faculty of Medicine, ethics committee vote number 427/17 s) and informed consent was taken from all individual participants.

\section{Surgical procedure}

All open-heart surgeries were performed through a midline sternotomy with standard bypass cannulation, moderate hypothermia $\left(34^{\circ} \mathrm{C}\right)$, and antegrade crystalloid cardioplegia. The diseased aortic valve leaflets were excised and annular calcium was debrided using conventional surgical techniques. The annulus was measured using the Edwards Lifesciences barrel sizer and the replica. Three equidistant guiding sutures were placed through the native annulus at the nadir of each cusp and then through the corresponding position of the valve sewing ring. It should be noted that the use of sutures with pledgets is not recommended because the pledgets may create paravalvular leaks. By using the specialized delivery system, the valve was lowered onto the annulus using the three guiding sutures. After the valve was seated, the balloon catheter was expanded to a nominal inflation pressure of 4.5 bar for valve sizes up to \#23, and 5.0 bar for valve sizes \#25 and \#27 and was maintained for 10 seconds to ensure proper frame expansion. After deployment, the delivery system was removed, guiding sutures were tied, and the aortotomy was closed in routine fashion (Figure 2).

\section{Pacemaker procedures}

In this analysis, pacemakers implanted before discharge after successful implantation of the Edwards INTUITY valve are reported. The event of PPI following AVR was retrieved from our institutional database and indications for pacemaker implantation and timing were reviewed. Each 


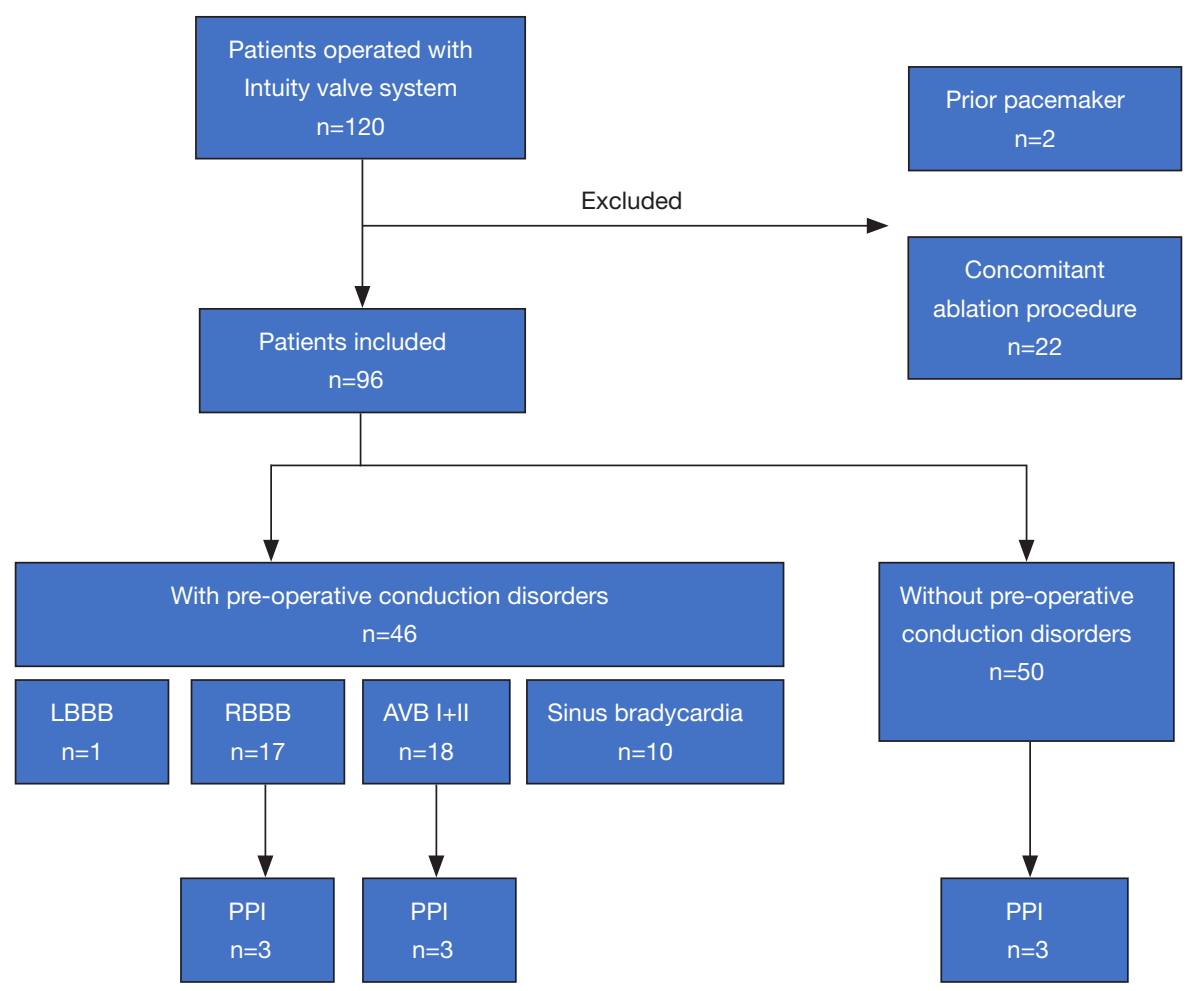

Figure 1 Trial profile. LBBB, left bundle branch block; RBBB, right bundle branch block; AVB, atrio-ventricular block; PPI, permanent pacemaker implantation.

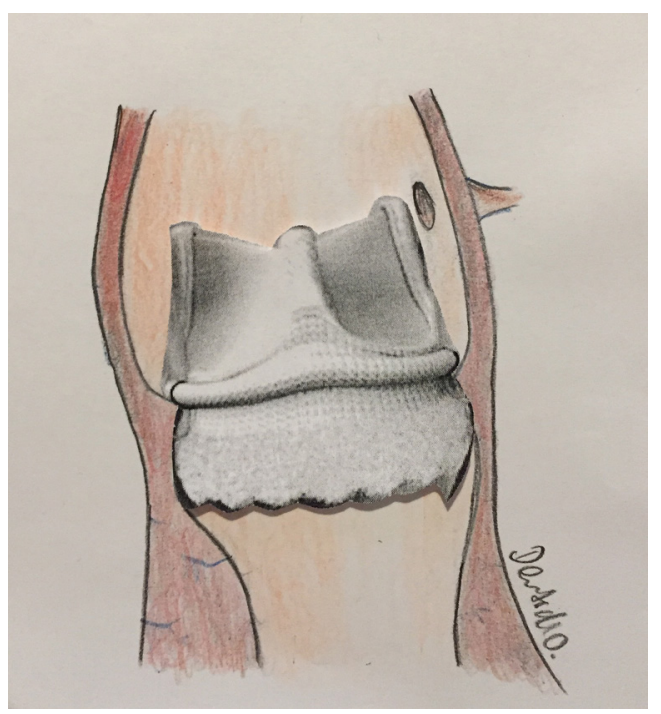

Figure 2 Correct seating position of the Intuity valve.

PPI was documented with perioperative drug management, detailed operational notes, and accompanying pre-PPI ECG. Baseline conduction abnormalities included atrial fibrillation, atrio-ventricular block (AVB) of type I or II, complete or incomplete right bundle branch block (RBBB), complete or incomplete left bundle branch block (LBBB), and sinus bradycardia. Time to PPI was assessed as the number of days between PPI and AVR.

\section{Statistical methods}

Our aim was to identify pre-existing conditions that were associated with all cause PPI in the early postoperative phase. We first conducted univariate analyses including various parameters. Based upon the outcome of these univariate analyses and clinical judgement, we developed a multivariate logistic regression model ultimately including 5 variables: patient age, patient sex, valve size, presence or absence of AVB (type I or II), and presence or absence of complete or incomplete RBBB. The output of the multivariate model whose parameters judged to be associated with all cause PPI through discharge were those whose $\mathrm{P}<0.05$. Continuous data are presented as means \pm standard deviation. Categorical data are presented as counts and percentages. Statistical analysis was completed using 
Table 1 Patient characteristics of the investigational cohort ( $\mathrm{n}=96)$

\begin{tabular}{ll}
\hline Parameter & $\mathrm{n}:$ mean $\pm \mathrm{SD}, \%(\mathrm{n} / \mathrm{N})$ \\
\hline Age (years) & $69.5 \pm 7.6$ \\
EuroScore II & $96: 3.2 \pm 2.9$ \\
Male & $74 \%(71 / 96)$ \\
Body mass index $\left(\mathrm{kg} / \mathrm{m}^{2}\right)$ & $96: 22.3 \pm 9.8$ \\
NYHA Class I or II & $16.7 \%(16 / 96)$ \\
NYHA Class III & $31.2 \%(30 / 96)$ \\
NYHA Class IV & $52.1 \%(50 / 96)$ \\
Sinus rhythm & $100 \%(96 / 96)$ \\
Pre-op conduction abnormalities & $47.9 \%(46 / 96)$ \\
Sinus bradycardia & $10.4 \%(10 / 96)$ \\
RBBB & $17.7 \%(17 / 96)$ \\
LBBB & $1.0 \%(1 / 96)$ \\
AV block & $18.8 \%(18 / 96)$ \\
AV block I & $17.7 \%(17 / 96)$ \\
AV block II & $1.0 \%(1 / 96)$ \\
\hline
\end{tabular}

Subjects without sinus bradycardia, atrial fibrillation, AV block, right bundle branch block, and left bundle branch block, were considered free from baseline conduction abnormalities. CABG, coronary artery bypass grafting; NYHA, New York Heart Association; RBBB, right bundle branch block; LBBB, left bundle branch block; $\mathrm{AV}$, atrioventricular.

IBM SPSS Statistics for Windows, version 25 (IBM Corp., Armonk, NY, USA).

\section{Results}

Two patients with prior pacemaker implantation (2/120, $1.7 \%$ ) and 22 patients with concomitant ablation procedures $(22 / 120,18.3 \%)$ were excluded from the analysis. Patientspecific, procedural and post-procedural outcomes were assessed in the remaining 96 cases. AVR was successful in all cases. Concomitant procedures included CABG in 73 patients $(73 / 96,79.1 \%)$, replacement of the ascending aorta in $8(8 / 96,8.3 \%)$, mitral valve repair in 14 (14/96, $14.6 \%)$, tricuspid valve repair in $8(8 / 96,8.3 \%)$ and mitral valve replacement in 2 patients $(2 / 96,2.1 \%)$. There were no intraoperative and one in-hospital $(1 / 96,1.0 \%)$ death at day 6 following the procedure. The cause of death was mesenteric ischemia following triple coronary artery bypass grafting and AVR with Edwards INTUITY Valve System size 21 . The last available postoperative electrocardiograms demonstrated no conduction disorders.

\section{Patient demographics and baseline characteristics}

Male gender of the study population was $74 \%$ with a mean age of $69.5 \pm 7.6$ years. EuroSCORE II was $3.2 \pm 2.9$. Preoperative ECG revealed conduction disorders in 46 patients (46/96, 47.9\%), specifically sinus bradycardia (10/96, $10.4 \%), \operatorname{LBBB}(1 / 96,1.0 \%), \operatorname{RBBB}(17 / 96,17.7 \%)$ and first-degree or second degree AVB (18/96, 18.8\%). Patient demographics and baseline characteristics are shown in Table 1 and intraoperative and postoperative data are shown in Table 2.

\section{PPI incidence, indication, and timing}

Incidence of PPI in the whole collective was 9.4\% (9/96). 3 patients (3/50,6\%) who did not have a pre-existing conduction disorder exhibited a new AVB grade III. Six patients with pre-operative conduction disorders (6/46, $13 \%)$ needed a PPI. Of these, three patients had preexisting RBBB $(3 / 46,6 \%)$ and three patients had first-degree AVB (3/46, 6\%); the indication for PPI was symptomatic, slow atrial fibrillation in two patients $(2 / 46,4.3 \%)$ and thirddegree AVB in four patients (4/46, 8.6\%). The mean size of implanted valves in patients with and without PPI was $25.7 \pm 1.4$ (median 25) vs. 23.6 \pm 2.2 (median 23), respectively $(\mathrm{P}=0.56)$. Timing of PPI was $5.2 \pm 1.5$ days (median 5$)$ after AVR. The proportion of PPI performed within $\leq 4$ days was $33 \%$. Figure 3 shows the timing of the 9 PPIs implanted pre-discharge.

\section{Baseline predictors of PPI}

The results of the multivariate analysis assessing the association of various patient baseline characteristics or conditions to all cause PPI are illustrated in a Forest plot (Figure 4). Higher incidence of PPI was associated with large valve size (\#27) [odds ratio $(\mathrm{OR})=5.527$, 95\% confidence interval: $1.285-23.774, \mathrm{P}=0.031$ ], and preoperative $\mathrm{RBBB}(\mathrm{OR}=4.554,1.078-19.237, \mathrm{P}=0.049$ ). Borderline significance was noted with male gender (OR $=0.69,0.599-0.794, \mathrm{P}=0.057)$. Pre-existing AVB I or II (OR $=2.846,0.631-12.833, \mathrm{P}=0.169)$ and larger valve sizes $(\# 25$ plus \#27, OR =3.581, 0.704-18.219, $\mathrm{P}=0.162$ ) did not reach significance. A listing of all variables analyzed, is included in the Supplementary file (Table S1). 
Table 2 Intraoperative and postoperative patient data $(\mathrm{n}=96)$

\begin{tabular}{|c|c|}
\hline Parameter & $\begin{array}{l}\mathrm{n}: \text { mean } \pm \mathrm{SD} \text {; median (range); } \\
\%(\mathrm{n} / \mathrm{N})\end{array}$ \\
\hline Aortic cross-clamp time (min) & $90.3 \pm 27.4 ; 94(37-136)$ \\
\hline CPB time (min) & $127 \pm 54.8 ; 121(51-204)$ \\
\hline Duration of surgery (min) & $284 \pm 90.6 ; 274$ (128-524) \\
\hline Reoperative surgery & $2.1 \%(2 / 96)$ \\
\hline \multicolumn{2}{|l|}{ Concomitant } \\
\hline CABG & $79.1 \%(73 / 96)$ \\
\hline Ascending aorta replacement & $8.3 \%(8 / 96)$ \\
\hline Mitral valve repair & $14.6 \%(14 / 96)$ \\
\hline Mitral valve replacement & $2.1 \%(2 / 96)$ \\
\hline Tricuspid valve repair & $8.3 \%(8 / 96)$ \\
\hline \multicolumn{2}{|l|}{ Prosthesis } \\
\hline Size 19 & $3.1 \%(3 / 96)$ \\
\hline Size 21 & $16.7 \%(16 / 96)$ \\
\hline Size 23 & $28.1 \%(27 / 96)$ \\
\hline Size 25 & $36.5 \%(35 / 96)$ \\
\hline Size 27 & $15.6 \%(15 / 96)$ \\
\hline Implantation of $>1$ prosthesis & 0 \\
\hline Cerebral ischemic events & $3.1 \%(3 / 96)$ \\
\hline Major bleeding & $6.2 \%(6 / 96)$ \\
\hline Renal replacement therapy & $4.2 \%(4 / 96)$ \\
\hline ECMO & 0 \\
\hline Deep sternal wound infection & $2.1 \%(2 / 96)$ \\
\hline Hospital stay (days) & $13.5 \pm 8.5 ; 12(6-59)$ \\
\hline Hospital mortality & $1 \%(1 / 96)$ \\
\hline
\end{tabular}

CPB, cardiopulmonary bypass; CABG, coronary artery bypass grafting; ECMO, extracorporeal membrane oxygenation.

\section{Post-implant presence of bundle branch block}

In those patients without pre-existing conduction disturbance and not receiving PPI, 7 patients $(7 / 50,14 \%)$ had new LBBB, 4 patients $(4 / 50,8 \%)$ had new RBBB, and 8 patients $(8 / 50$, $16 \%)$ had new onset first-degree AVB at discharge.

\section{Discussion}

\section{Incidence of PPI}

Anchoring of the rapid deployment aortic valve system

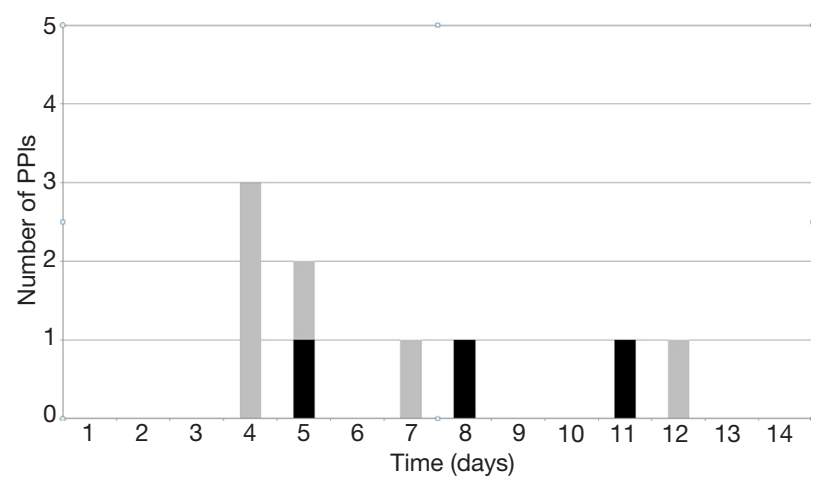

Figure 3 Permanent pacemaker implantation timing through discharge. Grey columns represent patients with pre-operative conduction disorders. Black columns represent patients without pre-operative conduction disorders. PPI, permanent pacemaker implantation.

relies on radial force exerted from a stent in the left ventricular outflow tract $(5,6)$. This may cause damage to the conduction system with subsequent need for PPI (7). In our cohort the primary indication for PPI was AVB, with an incidence of $9.4 \%$. Our results are comparable with a contemporary multicenter study by Romano, focusing on PPI following the implantation of the INTUITY valve in which the incidence of PPI was $12.3 \%$ (4). Published European studies report PPI rates between 1.7-9\% following implantation of the INTUITY valve $(2,4,8-11)$. The sutureless Perceval valve (Livanova PLC, London, UK) like the rapid deployment Intuity valve was developed to facilitate and increase the speed of surgical AVR, although the design is different. The PPI rates reported for that valve system are approximately $10 \%(12-14)$. In comparison, the PPI rates for conventional surgical AVR were recently reported to be $2.9 \%$ in the surgical arm of the Partner 3 trial (15).

\section{Pre-existing conduction disorders as prognostic indicators of PPI}

Approximately half of our patients presented with preexisting conduction abnormalities such as AVB (18.8\%) and RBBB (17.7\%), respectively. The current analysis clearly identifies pre-existing RBBB and large valve size as independent predictors of PPI following implantation of the Edwards INTUITY valve. Our finding is also supported by the current literature. In a study by Dawkins the presence of preoperative conduction abnormalities and specifically bundle branch block (BBB) have been shown to 
OR $(95 \% \mathrm{Cl})$

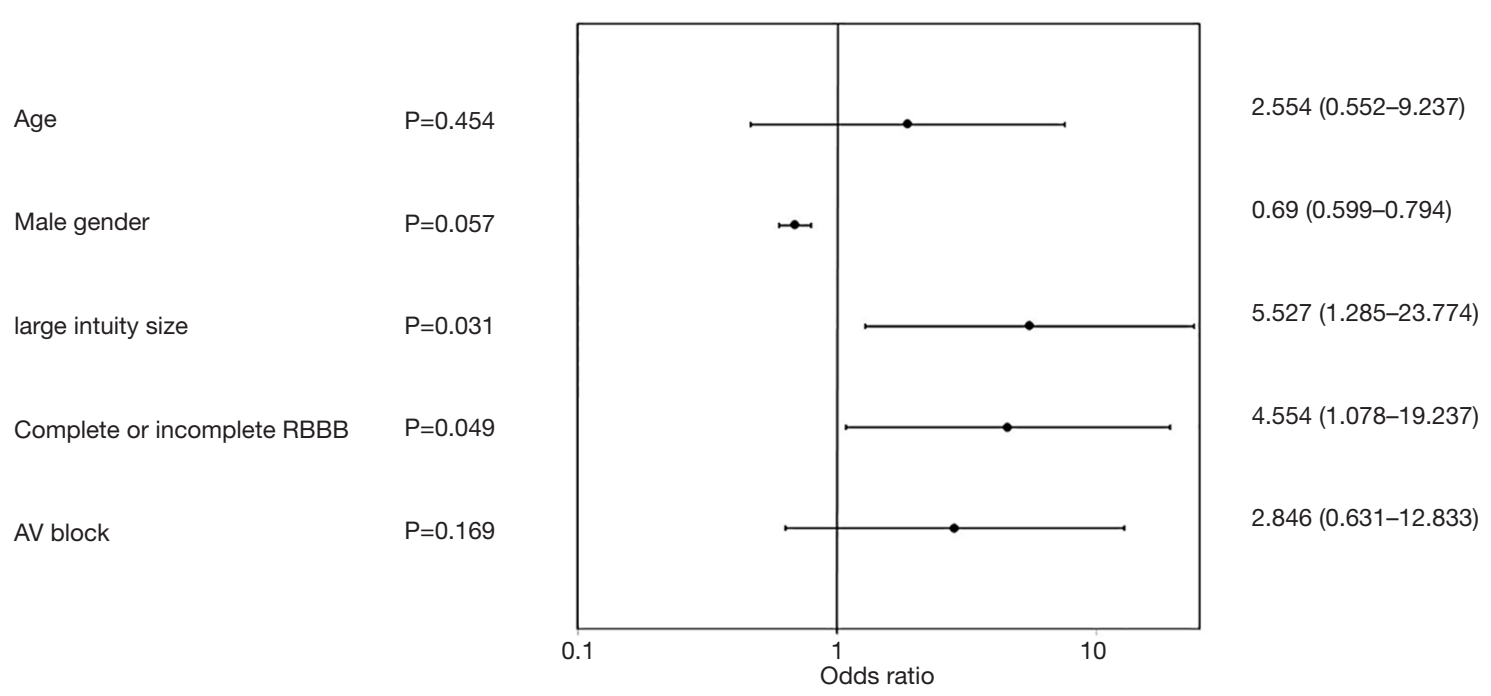

Figure 4 Forest plot of multivariate predictors of all cause permanent pacemaker implantation through discharge. AV, atrioventricular; $\mathrm{RBBB}$, right bundle branch block; OR, odds ratio; CI, confidence interval.

be predictors of PPI also in patients undergoing standard surgical AVR (16). Additionally, in a study by Van Mieghem, pre-existing BBB was associated with a significantly higher incidence of PPI following standard surgical AVR. In their study a BBB was present at baseline in $7 \%$ of patients, which resulted in a PPI rate of $8 \%$ compared to $1.5 \%$ in those without preoperative BBB (17). Moreover, the presence of BBB has been shown to be a predictor of PPI in patients undergoing transcatheter aortic valve replacement (TAVR) $(18,19)$. van Gils et al. published pooled data on 306 patients following TAVR in 4 high-volume centers in Europe. In a subgroup analysis $41 \%$ of the patients with RBBB at baseline required PPI, ranging from $34 \%$ to $75 \%$ depending on valve design (20). Vogt et al. identified RBBB as an independent predictor of postoperative conduction disorders in multivariate analysis using the sutureless Perceval valve (21).

\section{Valve size as risk factor for PPI}

In an earlier study at our institution focusing on new-onset complete heart block after TAVR we reported a 2 -fold increased risk for new-onset AVB in patients who received a large valve in a small annulus (22). However, one should bear in mind that experience from TAVR does not directly translate to surgical rapid deployment valves, since the technologies differ (e.g., valve resection and decalcification of the aortic annulus). Nevertheless, our results are supported by Romano et al. who showed that larger valve size was an independent predictor of PPI within 30 days following implantation of the INTUITY valve in a subanalysis of the TRANSFORM trial. Other factors associated with the incidence of PPI (12.3\% to discharge) were RBBB and female gender, whereas borderline significance was noted with AVB (4).

\section{Other factors influencing the incidence of PPI and optimal timing of PPI}

In the present study, we included only patients with concomitant procedures, such as coronary artery bypass grafting, replacement of the ascending aorta, mitral valve repair, mitral valve replacement, and tricuspid valve repair. The nature of the concomitant procedures had no significant effect on the incidence of PPI in our study. Furthermore, the rate of PPI did not change over the study interval, suggesting that a potential "learning curve" had also no influence. While our median time to PPI was on the 5 th postoperative day, $33 \%$ of the patients received a pacemaker within 4 days following surgery. Pharmacologic management of atrial fibrillation and heart failure medications like beta-blockers may exacerbate 
conduction abnormalities. Therefore, it is our standard practice to discontinue all medications which might cause bradycardia in patients with postoperative AVB or bradyarrhythmias before the indication for PPI is decided. Current ESC/EHRA guidelines recommend an observation period of 5-7 days before implanting a permanent pacemaker; this potentially allows for regression of transient brady-arrhythmias or conduction disturbances (Class 1 recommendation) (23). Current ACC/AHA guidelines recommend permanent pacing before discharge in patients who have new postoperative sinus node dysfunction or AVB associated with persistent symptoms or hemodynamic instability that does not resolve after AVR (Class 1 recommendation). However, the decision regarding the timing of PPI is deferred to the physicians' discretion by the US guidelines (24).

\section{New onset conduction disorders and late PPI}

Several studies suggested that the need for PPI occurs mostly early after implantation of the INTUITY valve, similar to standard AVR. Therefore, our study focused on early, pre-discharge PPI and did not include post-discharge pacemaker interrogation data. In the present study 19 patients $(19 / 50,38 \%)$ without pre-existing conduction disturbance had new onset of $\mathrm{LBBB}, \mathrm{RBBB}$, or firstdegree AVB at discharge but did not receive a PPI. In a recent single-center study focusing on new postoperative conduction abnormalities after the implantation of the INTUITY valve the incidence of new conduction abnormalities after surgery was 50.2\% (LBBB, RBBB or new AV block III) which is considerably higher than the pre-discharge PPI rate of $9.7 \%$ (25). Similarly, another study reported an incidence of $30 \%$ new LBBB after TAVR using a balloon-expandable device. However, almost $60 \%$ of those patients exhibited a normal electrocardiogram at 1 -year follow-up (26). Reports are conflicting as to whether these patients can recover from conduction disturbances, in particular LBBB (25).

\section{Conclusions}

The analysis of the data collected enabled us to identify patient factors associated with higher risk for post-operative PPI following AVR with the INTUITY valve. Patient factors associated with PPI after rapid deployment AVR, were RBBB and large valve size. These patients should be closely monitored following the procedure, in particular.

\section{Study limitations}

This study is not a randomized study and, thus, carries the natural limitations. On the other hand, this large singlecenter study deriving its data from our institutional database reflects some real-world experience.

\section{Acknowledgments}

Funding: None.

\section{Footnote}

Reporting Checklist: The authors have completed the STROBE reporting checklist. Available at http://dx.doi. org/10.21037/jtd-20-3120

Data Sharing Statement: Available at http://dx.doi. org/10.21037/jtd-20-3120

Conflicts of Interest: All authors have completed the ICMJE uniform disclosure form (available at http:// dx.doi.org/10.21037/jtd-20-3120). RL reports other from Medtronic, other from Abbott, other from Highlife, outside the submitted work. MK serves as unpaid editorial board member of Fournal of Thoracic Disease from Aug 2019 to Jul 2021. The other authors have no conflicts of interest to declare.

Ethical Statement: The authors are accountable for all aspects of the work in ensuring that questions related to the accuracy or integrity of any part of the work are appropriately investigated and resolved. The study was conducted in accordance with the Declaration of Helsinki (as revised in 2013). The study was approved by institutional ethics committee (Technical University Munich, Faculty of Medicine, ethics committee vote number 427/17 s) and informed consent was taken from all individual participants.

Open Access Statement: This is an Open Access article distributed in accordance with the Creative Commons Attribution-NonCommercial-NoDerivs 4.0 International License (CC BY-NC-ND 4.0), which permits the noncommercial replication and distribution of the article with the strict proviso that no changes or edits are made and the original work is properly cited (including links to both the formal publication through the relevant DOI and the license). See: https://creativecommons.org/licenses/by-nc-nd/4.0/. 


\section{References}

1. Borger MA, Moustafine V, Conradi L, et al. A randomized multicenter trial of minimally invasive rapid deployment versus conventional full sternotomy aortic valve replacement. Ann Thorac Surg 2015;99:17-25.

2. Kocher AA, Laufer G, Haverich A, et al. One-year outcomes of the Surgical Treatment of Aortic Stenosis With a Next Generation Surgical Aortic Valve (TRITON) trial: a prospective multicenter study of rapid-deployment aortic valve replacement with the EDWARDS INTUITY Valve System. J Thorac Cardiovasc Surg 2013;145:110-5; discussion 115-6.

3. Barnhart GR, Accola KD, Grossi EA, et al. TRANSFORM (Multicenter Experience With Rapid Deployment Edwards INTUITY Valve System for Aortic Valve Replacement) US clinical trial: Performance of a rapid deployment aortic valve. J Thorac Cardiovasc Surg 2017;153:241-251.e2.

4. Romano MA, Keckert M, Mutmaß MA, et al. Permanent Pacemaker Implantation After Rapid Deployment Aortic Valve Replacement. Ann Thorac Surg 2018;106:685-90.

5. Fadahunsi OO, Olowoyeye A, Ukaigwe A, et al. Incidence, Predictors, and Outcomes of Permanent Pacemaker Implantation Following Transcatheter Aortic Valve Replacement: Analysis From the U.S. Society of Thoracic Surgeons/American College of Cardiology TVT Registry. JACC Cardiovasc Interv 2016;9:2189-99.

6. Bouhout I, Mazine A, Rivard L, et al. Conduction Disorders After Sutureless Aortic Valve Replacement. Ann Thorac Surg 2017;103:1254-60.

7. Steinberg BA, Harrison JK, Frazier-Mills C, et al. Cardiac conduction system disease after transcatheter aortic valve replacement. Am Heart J 2012;164:664-71.

8. Andreas M, Wallner S, Habertheuer A, et al. Conventional versus rapid-deployment aortic valve replacement: a singlecentre comparison between the Edwards Magna valve and its rapid-deployment successor. Interact Cardiovasc Thorac Surg 2016;22:799-805.

9. Borger MA, Dohmen PM, Knosalla C, et al. Haemodynamic benefits of rapid deployment aortic valve replacement via a minimally invasive approach: 1-year results of a prospective multicentre randomized controlled trial. Eur J Cardiothorac Surg 2016;50:713-20.

10. Theron A, Gariboldi V, Grisoli D, et al. Rapid Deployment of Aortic Bioprosthesis in Elderly Patients With Small Aortic Annulus. Ann Thorac Surg 2016;101:1434-41.

11. Wahlers TC, Haverich A, Borger MA, et al. Early outcomes after isolated aortic valve replacement with rapid deployment aortic valve. J Thorac Cardiovasc Surg 2016;151:1639-47.

12. Berretta P, Andreas M, Carrel TP, et al. Minimally invasive aortic valve replacement with sutureless and rapid deployment valves: a report from an international registry (Sutureless and Rapid Deployment International Registry). Eur J Cardiothorac Surg 2019;56:793-9.

13. Muneretto C, Alfieri O, Cesana BM, et al. A comparison of conventional surgery, transcatheter aortic valve replacement, and sutureless valves in "real-world" patients with aortic stenosis and intermediate- to high-risk profile. J Thorac Cardiovasc Surg 2015;150:1570-7; discussion 1577-9.

14. Santarpino G, Pfeiffer S, Jessl J, et al. Sutureless replacement versus transcatheter valve implantation in aortic valve stenosis: a propensity-matched analysis of 2 strategies in high-risk patients. J Thorac Cardiovasc Surg 2014;147:561-7.

15. Mack MJ, Leon MB, Thourani VH, et al. Transcatheter Aortic-Valve Replacement with a Balloon-Expandable Valve in Low-Risk Patients. N Engl J Med 2019;380:1695-705.

16. Dawkins S, Hobson AR, Kalra PR, et al. Permanent pacemaker implantation after isolated aortic valve replacement: incidence, indications, and predictors. Ann Thorac Surg 2008;85:108-12.

17. Van Mieghem NM, Head SJ, de Jong W, et al. Persistent annual permanent pacemaker implantation rate after surgical aortic valve replacement in patients with severe aortic stenosis. Ann Thorac Surg 2012;94:1143-9.

18. Mauri V, Deuschl F, Frohn T, et al. Predictors of paravalvular regurgitation and permanent pacemaker implantation after TAVR with a next-generation selfexpanding device. Clin Res Cardiol 2018;107:688-97.

19. Auffret V, Webb JG, Eltchaninoff H, et al. Clinical Impact of Baseline Right Bundle Branch Block in Patients Undergoing Transcatheter Aortic Valve Replacement. JACC Cardiovasc Interv 2017;10:1564-74.

20. van Gils L, Tchetche D, Lhermusier T, et al. Transcatheter heart valve selection and permanent pacemaker implantation in patients with pre-existent right bundle branch block. J Am Heart Assoc 2017;6:e005028.

21. Vogt F, Pfeiffer S, Dell'Aquila AM, et al. Sutureless aortic valve replacement with Perceval bioprosthesis: are there predicting factors for postoperative pacemaker implantation? Interact Cardiovasc Thorac Surg 2016;22:253-8.

22. Bleiziffer S, Ruge H, Horer J, et al. Predictors for new- 
onset complete heart block after transcatheter aortic valve implantation. JACC Cardiovasc Interv 2010;3:524-30.

23. Brignole M, Auricchio A, Baron-Esquivias G, et al. 2013 ESC Guidelines on cardiac pacing and cardiac resynchronization therapy: the Task Force on cardiac pacing and resynchronization therapy of the European Society of Cardiology (ESC). Developed in collaboration with the European Heart Rhythm Association (EHRA). Eur Heart J 2013;34:2281-329.

24. Kusumoto FM, Schoenfeld MH, Barrett C, et al. 2018 ACC/AHA/HRS Guideline on the Evaluation and Management of Patients With Bradycardia and Cardiac Conduction Delay: Executive Summary: A Report of

Cite this article as: Deutsch O, Deisenhofer I, Koch-Buettner K, Lange R, Krane M. Need for permanent pacemaker implantation following implantation of the rapid deployment valve in combined procedures: a single centre cohort study. J Thorac Dis 2021;13(4):2128-2136. doi: 10.21037/ jtd-20-3120 the American College of Cardiology/American Heart Association Task Force on Clinical Practice Guidelines, and the Heart Rhythm Society. J Am Coll Cardiol 2019;74:932-87.

25. Mogilansky C, Balan R, Deutsch C, et al. New postoperative conduction abnormalities after the implantation of a rapid-deployment aortic valve prosthesis. Interact Cardiovasc Thorac Surg 2019;28:581-6.

26. Urena M, Mok M, Serra V, et al. Predictive factors and long-term clinical consequences of persistent left bundle branch block following transcatheter aortic valve implantation with a balloon-expandable valve. J Am Coll Cardiol 2012;60:1743-52. 
Supplementary

Table S1 Listing of all variables analyzed

\begin{tabular}{|c|c|c|c|}
\hline Variable & \multicolumn{3}{|c|}{$P$ value } \\
\hline Age $>60$ years & - & 0.350 & 0.435 \\
\hline Euro score $I I \geq 7 \%$ & 0.863 & - & - \\
\hline Bypass time & 0.290 & - & - \\
\hline Gender & - & 0.051 & 0.059 \\
\hline Ejection fraction $\leq 30 \%$ & - & 0.751 & 0.559 \\
\hline NYHA III or IV & - & 0.233 & 0.437 \\
\hline $\mathrm{BMI}\left(\mathrm{kg} / \mathrm{m}^{2}\right) \geq 30$ & - & 0.376 & 0.679 \\
\hline Valve size 23 & - & 0.268 & 0.328 \\
\hline Valve size 25 & - & 0.102 & 0.160 \\
\hline Valve size 27 & - & 0.011 & 0.041 \\
\hline Sinus rhythm & - & 0.402 & 0.395 \\
\hline Sinus bradycardia & - & 0.283 & 0.591 \\
\hline AV block I or II & - & 0.153 & 0.155 \\
\hline Complete/incomplete RBBB & - & 0.031 & 0.045 \\
\hline Complete/incomplete LBBB & - & 0.746 & 0.906 \\
\hline
\end{tabular}

NYHA, New York Heart Association; BMI, body mass index; AV, atrioventricular; RBBB, right bundle branch block; LBBB, left bundle branch block. 